\title{
Influence of Blast Furnace Inner Volume on Solid Flow and Stress Distribution by Three Dimensional Discrete Element Method
}

\author{
Zhengyun FAN, ${ }^{1,2)}$ Satoru IGARASHI, ${ }^{1)}$ Shungo NATSUI, ${ }^{1)}$ Shigeru UEDA, ${ }^{1)}$ Tianjun YANG, ${ }^{2)}$ Ryo INOUE ${ }^{1)}$ \\ and Tatsuro ARIYAMA ${ }^{1)}$
}

1) Institute of Multidisciplinary Research for Advanced Materials, Tohoku University, 2-1-1 Katahira, Aoba-ku, Sendai 980-8577 Japan. $\quad 2$ ) School of Metallurgical and Ecological Engineering, University of Science and Technology Beijing, Beijing 100083, China.

(Received on May 20, 2010; accepted on July 12, 2010)

\begin{abstract}
Since the enlargement of blast furnace inner volume is generally carried out two dimensionally, the diameter of the throat, bosh and hearth increase with the inner volume, while the height is kept approximately constant. Due to these changes, blast furnace enlargement influences burden descending behavior and stress distribution in the furnace. The present investigation intends to elucidate the influence of the inner volume of the blast furnace on the solid flow and stress distribution through a three-dimensional analysis by the discrete element method (DEM). Firstly, the enlargement of blast furnace volume increases the deadman volume in the lower part of the blast furnace in accordance with the previous study. As a result of this change in the deadman volume, the solid motion in the lower furnace is influenced by the enlargement of blast furnace inner volume. In large blast furnaces, the stress between particles near the wall at bosh level is suppressed due to the active particle movement between the wall and the deadman, and at the same time, the particles in these regions tend to cause slipping. The profile of the blast furnace, such as the bosh and shaft angle, has little influence on these phenomena. Totally, the blast furnace inner volume has an effect on the stability of solid movement through the enlarged deadman.
\end{abstract}

KEY WORDS: ironmaking; blast furnace; deadman; solid flow; stress distribution; discrete element method; burden descent; slipping.

\section{Introduction}

At present, the inner volume of blast furnaces is frequently enlarged at the time of furnace relining in order to secure a higher production rate. The enlargement of blast furnaces is generally carried out by two-dimensional upscaling. Low reducing agent operation in blast furnaces is also an important subject in the steel industry. However, low reducing agent operation in large blast furnaces possibly causes ill-balanced gas flow and solid flow, and in this case, operational stability and the productivity of the blast furnace tend to be sensitive. ${ }^{1)}$ Accordingly, in large blast furnaces with low reducing agent operation, non-uniform phenomena in the radial direction tend to increase and cause complex burden behavior, mainly in the lower part of the blast furnace, due to the large diameter of this part. ${ }^{1,2)}$ As often pointed out, the relative deadman volume increases with the enlargement of blast furnace inner volume. ${ }^{3)}$ Therefore, methods of forecasting and controlling in-furnace behavior, such as burden descent, are desired.

Numerical simulation analysis for the blast furnace makes it possible to understand those in-furnace phenomena. A numerical simulation based on a continuum model has been successfully developed. ${ }^{4,5)}$ However, the results obtained by the continuum model cannot reflect the mi- crostructure and non-uniform behavior of the solid flow in the blast furnace. The discrete element method (DEM) ${ }^{6)}$ is a method of simulating the motion of solid particles by tracing the motion of every particle based on the interactive force between particles at every time step, and can be used with favorable results to clarify discontinuous phenomenon and the non-uniform motion of the particle flow in an unsteady state at the microscopic level. Actually, DEM has been applied to simulate the solid flow in the blast furnace by some researchers. ${ }^{7-12)}$

Based on the background outlined above, this study focuses on the changes in the three-dimensional solid flow and stress distribution accompanying the enlargement of blast furnace inner volume based on DEM analysis. Regarding the stress distribution formed in the blast furnace, Shimizu analyzed the influence of the shaft angle on the stress field by a reduced-scaled model, ${ }^{13)}$ and Katayama proposed a theoretical model using elastic-plastic theory. ${ }^{14)}$ However, these studies are based on a continuum model derived from powder mechanics. In the present study, the macroscopic and microscopic behavior of the particle velocity and stress of each particle was analyzed by DEM in order to understand visually the burden descent. The influence of the inner volume of the blast furnace on the solid flow was also examined. 


\section{Structure of Simulation Model}

\subsection{Governing Equation of DEM}

In DEM, all forces acting on each particle are modeled and calculated based on a Voigt model consisting of a spring-dashpot and a slider at every time step, as shown in Fig. 1(a). The interactive force between the particles is shown in Fig. 1(b).

The normal force $F_{n, i j}$ and the tangential force $F_{t, i j}$ are derived as,

$$
F_{n, i j}=\left(K_{n} \Delta u_{n, i j}+\eta_{n} \frac{\Delta u_{n, i j}}{\Delta t}\right) n_{i j}
$$

and,

$$
\begin{aligned}
& F_{t, i j}=\min \left\{\mu\left|F_{n, i j}\right| t_{i j},\left[K_{t}\left(\Delta u_{n, i j}+\Delta \varphi_{i j}\right)\right.\right. \\
& \left.\left.+\eta_{t} \frac{\Delta u_{n, i j}+\Delta \varphi_{i j}}{\Delta t}\right] t_{i j}\right\}
\end{aligned}
$$

Where $K, \eta$, and $\mu$ denote the spring coefficient, the damping coefficient and the sliding friction coefficient, respectively. $\Delta u$ and $\Delta \varphi$ denote the relative translational displacement of the gravitational center between two particles and the relative angular displacement caused by rotation, respectively. $n_{i j}$ and $t_{i j}$ denote the unite vector from the $i$-th particle to the $j$-th particle in the normal and tangential components. The subscripts $n$ and $t$ denote the normal direction and the tangential direction, respectively.

$K_{n}$ and $K_{t}$ are derived from Young's modulus (E) and Poisson's ratio $(\mathrm{P})$ as,

$$
K_{n}=\frac{2 b E}{3\left(1-P^{2}\right)}
$$

and,

$$
K_{t}=\frac{K_{n}}{2(1+P)}
$$

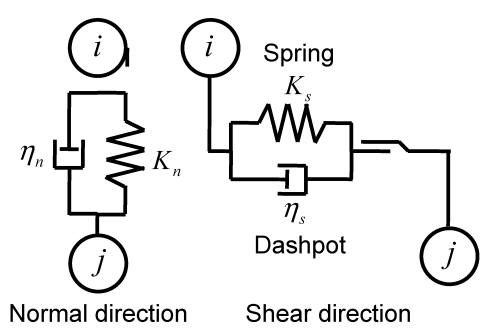

(a) The spring-dashpot contact model

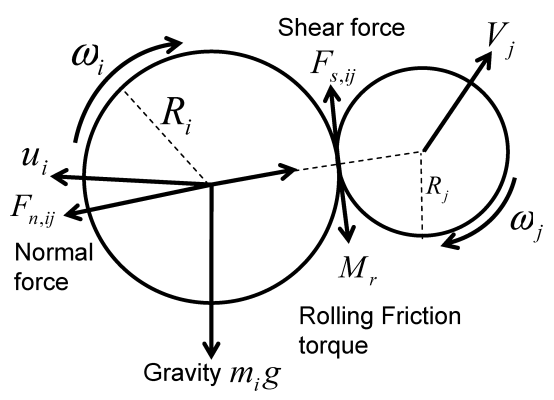

(b) Interactive force between two particles

Fig. 1. Element of discrete element method.
Where, $b$ denotes the radius of the contact circle.

The trajectory of a particle is obtained by the integration equations governing the translational motion and the rotational motion of a particle. The equations are shown as follows:

$$
m \frac{d v}{d t}=\sum F+m F_{g}
$$

and,

$$
I \frac{d \omega}{d t}=\sum\left(T+M_{r}\right)
$$

Where, $v, \omega$ denote the translational velocity and angular velocity, respectively, and $m$ is the mass of a particle. I denotes the moment of inertia of a particle, $T$ denotes a torque which is generated by elastic tangential force and viscous tangential force, $M_{r}$ is the rolling friction torque that resists the rotation of the particle and $\mathrm{F}$ is the force acting on the particle.

In order to represent the shape of coke and ore, rolling friction which mitigates the shear force acting on the contact circle was introduced..$^{9,10)}$ Rolling friction torque $M_{r}$ is defined as shown by the following expression:

$$
M_{r}=\frac{3}{8} \alpha b\left|F_{n}\right|
$$

Where, $a, b$ and $F_{n}$ are the rolling friction coefficient, the radius of the contact circle and normal force, respectively.

\subsection{Simulation Conditions}

The profiles of the blast furnaces in this simulation are shown in Table 1. The profile of an actual large blast furnace with an inner volume of $5775 \mathrm{~m}^{3}$ was adopted as a standard case (Case A)), and only the radius of this blast furnace was changed as shown in Table 1 to clarify the influence of the enlargement of the radius on solid behavior. As shown in Table 1, in the middle-size blast furnace with an inner volume of $3250 \mathrm{~m}^{3}$ (Case B)), the radius of each part of the blast furnace was adjusted by a factor of 0.75 relative to the dimensions of the large furnace, and the radius of small blast furnace with an inner volume of $1444 \mathrm{~m}^{3}$ (Case C)) was reduced by half that of the large furnace. In actual blast furnaces, the height changes slightly corresponding to the inner volume. However, in this simulation, the height was kept constant so as to consider independently the influence of the enlargement in the radial

Table 1. Profiles of blast furnaces used in calculations.

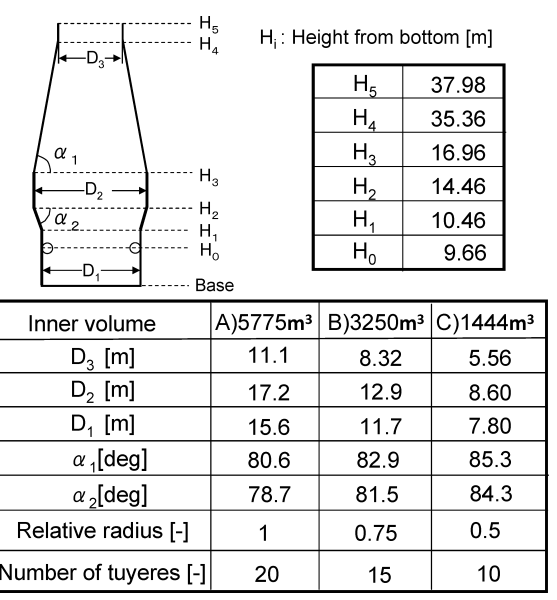


direction. The descending rate of the burden in the three blast furnaces is assumed to be identical in all cases in order to eliminate the effect of the descent velocity. The number of particles for each blast furnace is $3.5 \times 10^{5}$ for Case A), $2.0 \times 10^{5}$ for Case B) and $1.5 \times 10^{5}$ for Case C). The simulation time for burden descent in the DEM calculation is $180 \mathrm{~s}$. In order to represent same production rate for a unit volume, the coke consumption rate in the raceway of each blast furnace was adjusted to maintain the same descent velocity. Rate of coke consumption in raceway is $500 \mathrm{particles} / \mathrm{s}, 250 \mathrm{particles} / \mathrm{s}, 143 \mathrm{particles} / \mathrm{s}$ for large, middle, small blast furnace, respectively. Ore particles melt and disappeared at meting zone.

The individual particle of the burden is represented by a solid sphere. A semicircle blast furnace model with a wall which has no friction was employed to reduce the number of particles and accelerate calculations, as described above. The buoyancy effect of hot pig iron is not taken into account in the present simulation. The shape of the raceway is assumed to be sphere, and the diameter of the raceway was set at $1.6 \mathrm{~m}$. The particles that flow into the raceway disappear at a specified interval. Although the melting behavior of the ore is not discussed in this article, a cohesive line denoting the cohesive zone was included in this simulation. The height of the cohesive zone was set at $9.5 \mathrm{~m}$ above the tuyere level in the large blast furnace, and the relative shape of the cohesive zone was kept constant corresponding to the diameter of the hearth. When particles of ore descend across this line, they disappear immediately. Therefore, only particles of coke exist below the cohesive zone. The heights of the melting zone are set at $7.35 \mathrm{~m}$ for the $3250 \mathrm{~m}^{3}$ furnace and $5.20 \mathrm{~m}$ for the $1444 \mathrm{~m}^{3}$ furnace, respectively. Namely, the melting zone has a similar shape in both cases.

A simple bell-type charging device was employed. Coke and ore are charged alternately to keep the stock line in the same manner as in an actual blast furnace. Number of ore particles are 20756, 13830 , and 5040 for the three blast furnace and that of coke are 5320, 1030 , and 625. As shown in Table 2, the diameters of the coke and ore, Young's modulus and the friction coefficient are $0.3 \mathrm{~m}$ and $0.15 \mathrm{~m}, 5 \mathrm{Gpa}$ and 1.0 , considering previous studies. ${ }^{10,11)} \mathrm{In}$ some studies, Young's modulus was reduced to accelerate the calculation speed; however, in the present study, the actual value was adopted so as to simulate accurately the movement of particles in the blast furnace. To represent the shape factor of the particles and the particle motion, the optimum combination of sliding friction and rolling friction

Table 2. Simulation conditions and burden properties for DEM calculation.

\begin{tabular}{|c|c|c|c|}
\hline & coke & ore & \\
\hline Young's modulus & 5.0 & 5.0 & [GPa] \\
\hline Poisson's ratio & 0.21 & 0.24 & {$[-]$} \\
\hline Friction coefficient (p-p) & 1.0 & 1.0 & {$[-]$} \\
\hline Friction coefficient (p-w) & 0.7 & 0.7 & {$[-]$} \\
\hline Rolling friction coefficient & 2.5 & 1.25 & {$[-]$} \\
\hline Diameter of particle & 0.30 & 0.15 & [m] \\
\hline Density of particle & 1100 & 4000 & {$\left[\mathrm{~kg} / \mathrm{m}^{3}\right]$} \\
\hline Time step & \multicolumn{2}{|c|}{$1.0 \times 10^{-4}$} & {$[\mathrm{~s}]$} \\
\hline Simulation time & \multicolumn{2}{|c|}{180} & [s] \\
\hline
\end{tabular}

was introduced. The appropriate parameters for coke and ore are determined by the repose angle calculated by DEM. ${ }^{11)}$ The rolling friction coefficient was varied from 1.0 to 5.0, and the repose angle calculated by DEM was compared with that of the actual charged burden in the blast furnace. Because the density and size of coke and ore are different, the values of 2.5 and 1.25 were employed for the rolling friction coefficients of coke and ore, respectively. ${ }^{12)}$ The other properties of the particles and variables in this simulation are listed in Table 2.

\section{Feature of Burden Descent}

\subsection{Solid Motion and Deadman Volume}

In this calculation, ore and coke are charged alternately from the throat to keep the stock line and are discharged from the raceway at specified intervals to maintain a steady solid flow. A multi-layer packed bed structure composed of ore and coke is formed. The calculated distributions of the burden layer are shown in Fig. 2. In Figs. 2(A), 2(B) and 2(C) denote the $5775 \mathrm{~m}^{3}, 3250 \mathrm{~m}^{3}$ and $1444 \mathrm{~m}^{3}$ blast furnaces, respectively. Grey particles and red particles denote coke and ore. Particles are charged from the throat, and then roll to the center. As a result, the slope of the burden layer is formed naturally. Due to the collapse of the coke layer during ore charging, only coke particles were observed in the center of the large and middle-size blast furnaces.

The motion of the burden in blast furnaces is still composed of a steady flow and transient flow caused by slip around the raceway. ${ }^{15)}$ In a precise sense, velocity of burden varies by the every step. Figure 3 shows typical distribution of particle velocity in the steady state without charging and slip of burden for each blast furnace. As shown in Fig. 3, the particle velocity distribution mainly depends on the diameter of each part of the blast furnace, and a high descending velocity zone can be observed in the upper part of the blast furnace. Although a deadman, which has the lowest velocity, exists the lower part of the blast furnace, as shown in deep blue below the melting zone in Fig. 3, the shape of the deadman is not clear. These tendencies are common to Case A), Case B) and Case C) in Fig. 3.

Figure 4 shows the particle velocity distribution in the horizontal plane at the $\mathrm{H} 1+1 \mathrm{~m}$ level in the bosh part. In this height, ore exist only in outside. The deep blue particles show the stagnant region. From comparison of the three cases, a deadman region corresponding to the deep blue particles can be clearly observed in Case A). In Cases B) and C), the tendency of the particle velocity is different from that in Case A), and the stagnant zone in the center is not so clear as in Case A).

Figure 5 shows the streamlines and timelines calculated by DEM. Streamlines are shown for the trajectories of about ten particles selected at the throat. In Cases A) and B), the streamlines in the lower part of the furnace gradually change direction toward the raceway. These particles in the lower part take the shape of a funnel flow. On the contrary, in Case C), all particles descend almost vertically downwards. From the timelines in the lower part, the shape of the deadman, corresponding to stagnant movement, can be observed. The deadman shape can be estimated from the 
bold line shown in Fig. 5. The relative volume of the deadman above the tuyere level is shown in Fig. 6 for each blast furnace. From Fig. 6, it is obvious that the relative volume of the deadman increases with the enlargement of blast furnace inner volume.

\section{Distribution of Stress between Particles}

Normal stress $\sigma_{n}$ on particle $i$ can be calculated from the following Eq. (8).

$$
\sigma_{n}=\left(\sum F_{n, i j}\right) /\left(\pi D_{i}^{2}\right)
$$

Where, $F_{n, i j}$ are the normal force acting on particle $i$, and $D_{i}$ is the diameter of particle $i$. Figure 7 shows typical distribution of normal stress in the steady state without charging and slip of burden in the vertical cross section for each blast furnace. The red particles in Fig. 7 show high normal stress, and they mainly concentrated in the lower part. The

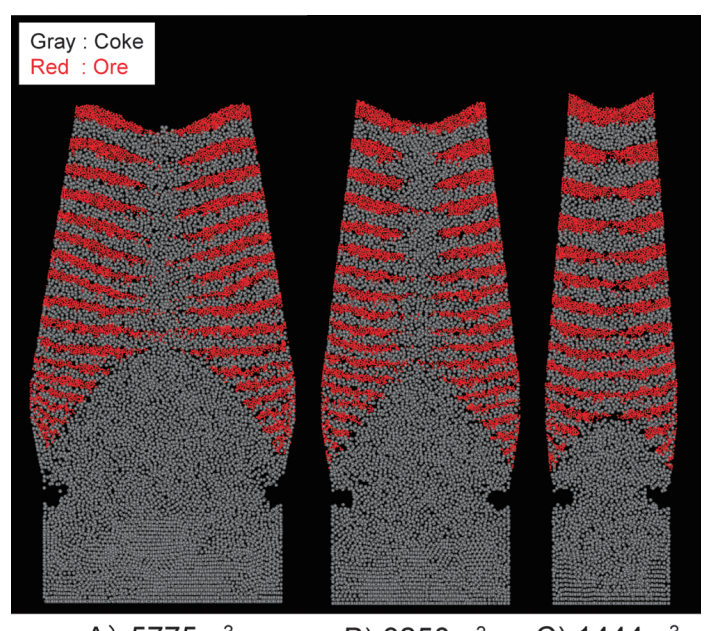
A) $5775 \mathrm{~m}^{3}$
B) $3250 \mathrm{~m}^{3}$
C) $1444 \mathrm{~m}^{3}$

Fig. 2. Calculated burden distribution by DEM.

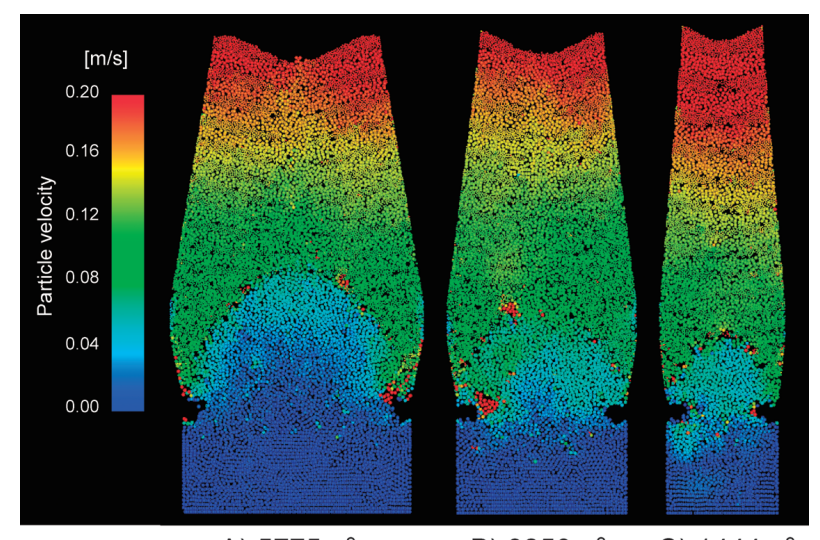

A) $5775 \mathrm{~m}^{3}$

B) $3250 \mathrm{~m}^{3}$

C) $1444 m^{3}$

Fig. 3. Particle velocity distribution calculated by DEM. formation of complicated stress networks in the blast furnace can be observed. The stress distribution in the present simulation shows a more complicated network than the result of the previous study. ${ }^{8)}$ It is estimated that these differences are derived from the conditions of particle hard-
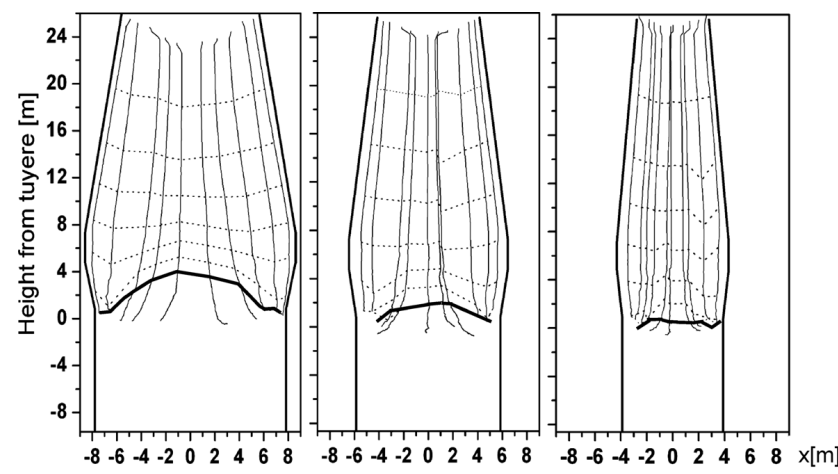

A) $5775 \mathrm{~m}^{3}$

B) $3250 \mathrm{~m}^{3}$

C) $1444 \mathrm{~m}^{3}$

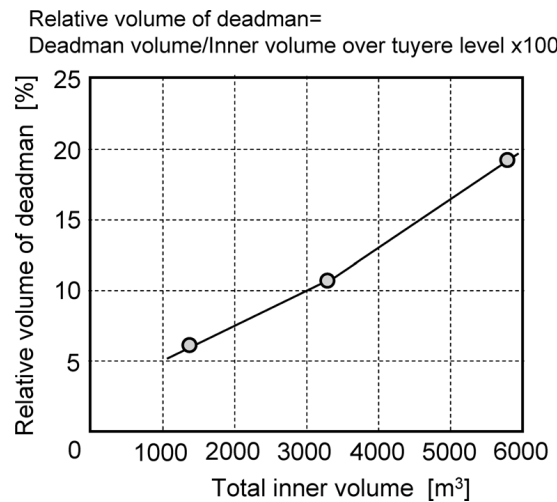

Fig. 6. Relationship between relative deadman volume and total inner volume.



A) $5775 m^{3}$

B) $3250 \mathrm{~m}^{3}$

C) $1444 m^{3}$

Fig. 7. Normal stress distribution between particles in whole blast furnace.

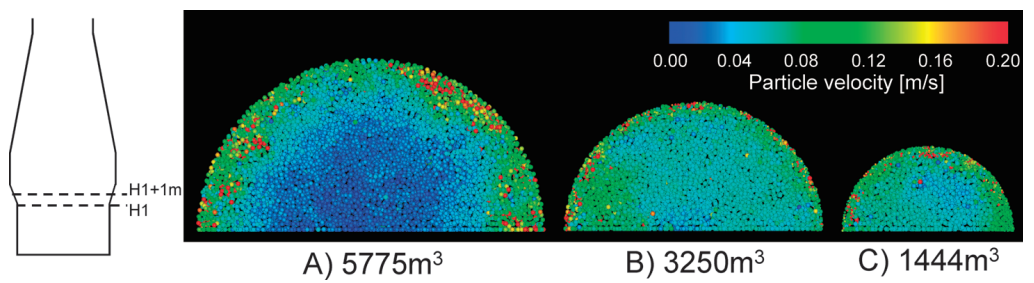

Fig. 4. Particle velocity distribution in horizontal plane at bosh level. 
ness, such as Young's modulus, and the boundary condition of the wall. In the previous research, ${ }^{8)}$ it was estimated that the stress distribution obtained would be affected by the wall due to the narrow $\left(10^{\circ}\right)$ sector model. Moreover, a soft particle condition was adopted in the simulation. In the case of soft particle hardness, the network tends to be consistent if contact conditions between particles are formed. The present study is based on a $180^{\circ}$ semicircular model for high accuracy and coke and ore particles with realistic particle hardness. Therefore, the results shown in Fig. 7 reflect the situation in the actual blast furnace with high accuracy. From Fig. 7, although the red particles with high normal stress concentrated in the center in the lower part of the furnace, their tendencies in the radial direction are different, as discussed in the following.

Figure 8 shows the normal stress distribution at bosh level $\left(\mathrm{H}_{1}+1 \mathrm{~m}\right)$ in the horizontal cross section. From Fig. 8, it is clear that the distribution of red particles with high normal stress in Case A) is different from those in Cases B) and C). In Cases B) and C), the red particles distribute uniformly in the horizontal plane. However, in Case A), their frequency decreases near the wall, and they mainly concentrate in the deadman region, as shown by the deep blue particles in Fig. 4. In order to clarify these differences, the horizontal distribution of the normal stress between particles along the radius at approximately the same level is shown in Fig. 9. In Fig. 9, the normal stress value was calculated for the particles between $\mathrm{H}_{1}$ and $\mathrm{H}_{1}+2 \mathrm{~m}$, and the particles for the calculation were selected from three particles layers so as to exclude the central axis, where the boundary effect became noticeable. It was estimated that the normal distribution was almost uniform in the radial direction in Cases B) and C). In Case B), some particles receive high normal stress near $10 \mathrm{MPa}$. Because the compressive strength of coke is generally considered to be approximately $15 \mathrm{MPa}$, it is possible that these particles collapsed as a result of normal stress. In Case A), the magnitude of the normal stress near the wall side became smaller than that in the central part. The normal stress between particles tends to decline in the region between the wall and the deadman in large blast furnaces. It was estimated that the stress network was weakened due to the high particle velocity in this region.

Based on the above results, the specification of burden strength for coke in the wall-side region in large blast furnaces could be controlled considering the normal stress distribution, corresponding to its compressive strength, because the wall-side coke in large blast furnaces did not receive compressive effects. However, strength against abrasion was regarded as an important factor due to the high particle velocity gradient for compressive strength. In contrast, in the case of middle-size and small blast furnaces, it was estimated that the quality of the coke must be uniform in all areas.

\section{Influence of Blast Furnace Profile on Burden Descent and Normal Stress}

It is conceivable that the distribution of normal stress could be influenced by the profile of the blast furnace, such as the shaft and bosh angle. Therefore, the profile of the blast furnace was intentionally changed so as to examine the influence of its profile on the particle velocity and normal stress distribution. Figure 10 shows the comparisons of the particle velocity and normal stress distribution in a large blast furnace corresponding to Case A) which has the same profile as that in Case $\mathrm{C}$ ), where each case has a same hearth diameter. In Fig. 10, the left part has an original profile, while the right part has a changed profile similar to Case C).

From Fig. 10, although the particle velocity on each case is influenced by the diameter, the overall tendency in the particle velocity and normal stress distribution was not remarkable. Accordingly, it was considered that the above results concerning the difference between the large blast furnace and the small blast furnace were caused by the enlarged diameter and in particular, the increase in the relative volume of the deadman. In the previous study, the profile of the blast furnace influenced the stress acting on the wall. ${ }^{14)}$ However, that study was based on a static analysis derived from powder mechanics. Because the present research con-
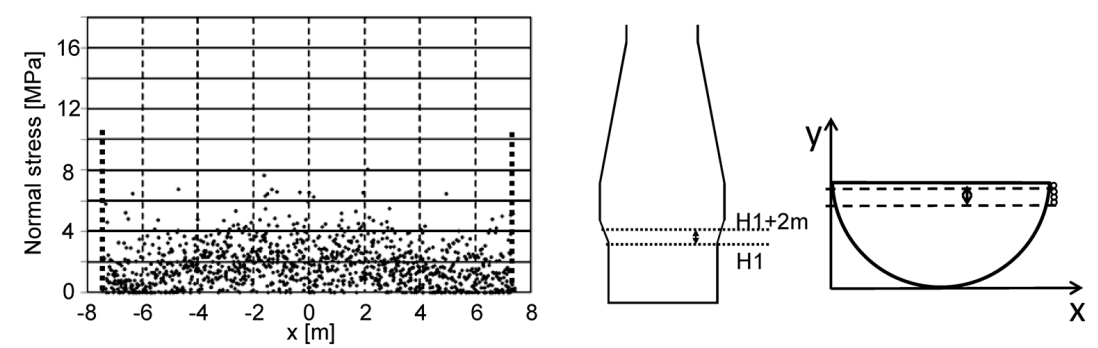

A) $5775 \mathrm{~m}^{3}$

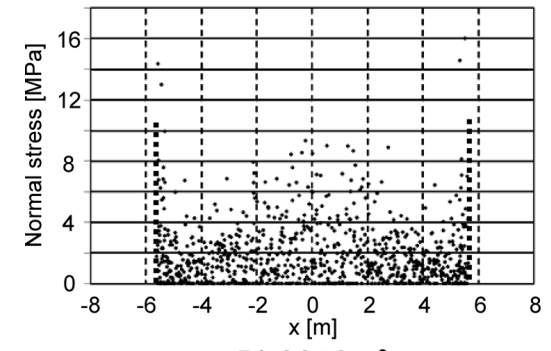

B) $3250 \mathrm{~m}^{3}$



C) $1444 \mathrm{~m}^{3}$

Fig. 9. Normal stress distribution between particles in radial direction at bosh level 
siders the solid dynamic movement and the normal stress between particles, the interaction between solid movement and normal stress was accurately represented three-dimensionally by DEM. Therefore, the inner state estimated in this research is considered to approximate the actual state in the blast furnace relatively closely.

\section{Stability of Burden Descending}

In order to clarify the relationship between the stress distribution and particle velocity, the stability of burden descent was examined. The following slipping factor index SLI was introduced to understand this phenomenon quantitatively. ${ }^{12)}$

$$
\mathrm{SLI}=\frac{F_{s}}{\mu F_{n}}
$$

where

$$
F_{n}=\sum_{j} F_{n, i j}
$$

and,

$$
F_{s}=\sum_{j}\left[K_{t}\left(\Delta u_{t, i j}+\Delta \varphi_{i j}\right)+\eta_{t} \frac{\Delta u_{t, i j}+\Delta \varphi_{i j}}{\Delta t}\right] t_{i j}
$$

The calculated SLI index is shown in Fig. 11. The red particles show a high SLI value; namely, these particles tend to cause local slipping. However, the tendency of the SLI dis- tribution in the whole blast furnace was not clear. Therefore, the distribution of the SLI index in the horizontal plane at bosh level was calculated, as shown in Fig. 12. Extent of stress on particle is relatively stable value, ${ }^{12}$ ) therefore the SLI distribution varies very slightly at every time step. In Fig. 12, the red particles with a high SLI index tend to concentrate near the wall. As described before, the particles between the deadman and the wall have a high descending velocity, and as a result, the high normal stress network was relaxed in this region of the large blast furnace. On the other hand, the weakened normal stress between particles caused unstable descent such as local slipping.

In the high particle velocity region, because a high stress network did not form due to the lack of arrangement of a stable packed bed, the particles did not receive high normal stress. This tendency became noticeable in the large blast furnace due to the formation of the enlarged deadman. However, these particles tend to cause local slipping. If some disturbance occurs in the lower part, it can possibly develop into slipping and irregular descending in a large blast furnace.

Figure 13 summarizes the total phenomena in the blast furnace. In the middle-size and small blast furnaces, the downward force acts uniformly in the radial direction to the lower part of the furnace. High normal stress regions developed uniformly at bosh level. On the contrary, in large blast

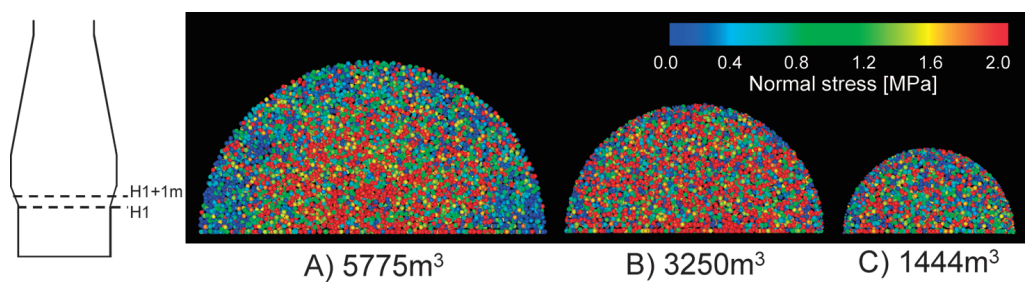

Fig. 8. Normal stress distribution between particles in horizontal plane at bosh level.

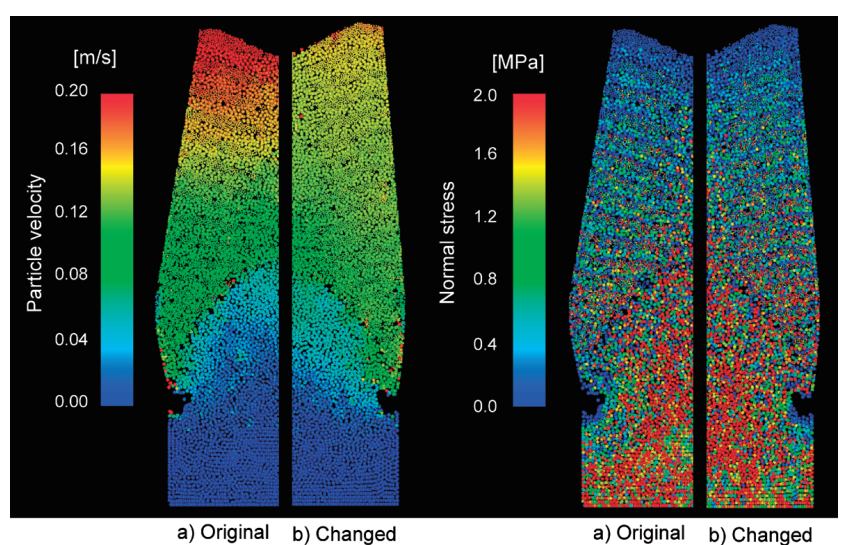

Fig. 10. Influence of blast furnace profile on particle velocity and normal stress distributions.

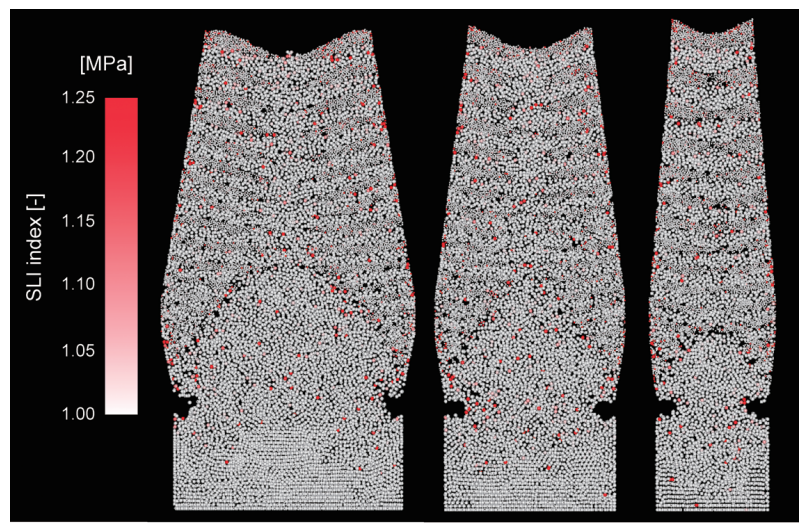

A) $5775 \mathrm{~m}^{3}$

B) $3250 \mathrm{~m}^{3}$

C) $1444 \mathrm{~m}^{3}$

Fig. 11. Slipping factor distribution in whole blast furnace.

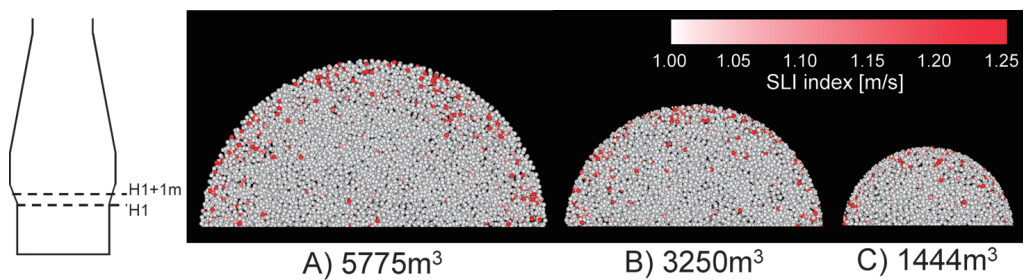

Fig. 12. Slipping factor distribution in horizontal plane at bosh level. 




Fig. 13. Influence of inner volume on solid flow and stress distribution.

furnaces such as that in Case A), the high normal stress region concentrates in the central area in the lower part of the blast furnace, and due to the high particle velocity between the wall and the deadman, the normal stress in the peripheral region is reduced. However, the particles in these regions tend to cause local slipping.

\section{Conclusions}

The three-dimensional discrete element method (DEM) was employed to investigate the influence of blast furnace inner volume on solid flow and stress distribution in the blast furnace. The following results were obtained.

(1) When the diameter of the blast furnace is enlarged, the relative deadman volume increases. This increase in deadman volume influences solid movement. In large blast furnaces with inner volumes over $5000 \mathrm{~m}^{3}$, the particles between the wall and the deadman have a large descending velocity. In contrast, in middle-size and small blast furnaces, the particles in the lower part show uniform burden descent.

(2) Regarding the normal stress between particles, complicated high stress networks were observed mainly in the central part. However, the distribution of normal stress in the radial direction shows a different tendency depending on the inner volume. In large blast furnaces, the normal stress values near the wall are reduced due to the high particle velocity in this region. In blast furnaces with the same inner volume, the profile of the furnace has little influence on these phenomena.

(3) The normal stress distribution and particle velocity influence the stability of burden descent. In the peripheral zone of large blast furnaces, particles tend to cause local slipping. Moreover, special attention should be given to control of the burden quality, considering the changes in compression and the abrasion mechanism at each position due to the above phenomena.

\section{REFERENCES}

1) T. Ariyama, M. Sato, T. Sato, S. Watakabe and R. Murai: Tetsu-toHagané, 92 (2006), 114.

2) T. Sato, M. Sato, K. Takeda and T. Ariyama: Tetsu-to-Hagané, 92 (2006), 1006.

3) M. Ichida, K. Anan, M. Takao, K. Kakimoto, Y. Morizane, I. Yamada and T. Nakayama: Shin-Nittetsu Giho, 384 (2006), 74.

4) J. A. De Castro, H. Nogami and J. Yagi: ISIJ Int., 42 (2002), 44.

5) H. Nogami, M. Chu and J. Yagi: Comput. Chem. Eng., 29 (2005), 2438.

6) P. A. Cundall and O. D. L. Strack: Geotechnique, 29 (1979), 47.

7) Z. Zhou, H. Zhu, A. Yu, B. Wright, D. Pinson and P. Zulli: ISIJ Int., 45 (2005), 1828.

8) T. Nouchi, T. Sato, M. Sato, K. Takeda and T. Ariyama: ISIJ Int., 45 (2005), 1426.

9) H. Mio, K. Yamamoto, A. Shimosaka, Y. Shirakawa and J. Hidaka: ISIJ Int., 47 (2007), 1745.

10) S. Natsui, S. Ueda, M. Oikawa, Z. Fan, J. Kano, R. Inoue and T. Ariyama: ISIJ Int., 49 (2009), 1308.

11) S. Natsui, S. Ueda, Z. Fan, J. Kano, R. Inoue and T. Ariyama: Tetsuto-Hagané, 96 (2010), 1.

12) S. Natsui, S. Ueda, Z. Fan, N. Anderson, J. Kano, R. Inoue and T. Ariyama: ISIJ Int., 50 (2010), 207.

13) M Shimizu, A. Yamaguchi, S Inaba and K. Narita: Tetsu-to-Hagané, 68 (1982), 936.

14) K. Katayama, S. Wakabayashi, T. Inada, K. Takatani and H. Yamaoka: Tetsu-to-Hagané, 83 (1997), 91.

15) Z. Fan, S. Natsui, S. Ueda, H. Nogami, J. Kano, R. Inoue and T. Ariyama: ISIJ Int., 50 (2010), 946. 